\title{
THE FUNCTIONS AND PRACTICES OF A TELEVISION NETWORK
}

\author{
Richard S. Salant,* Thomas K. Fisher, $†$ and Leon R. Brooks $\ddagger$
}

In the relatively short period of ten years, the television broadcasting industry has achieved a phenomenal growth. It is estimated that over 40 million families in the United States now have one or more television sets ${ }^{1}$ for which they have invested approximately $\$ 2 \mathrm{I} .0$ billion in their purchase and maintenance. ${ }^{2}$ The latest figures show that each television family averages slightly over five hours a day watching television. ${ }^{3}$ The universality of television is further evidenced by the fact that 99.2 per cent of United States families live in areas which are within range of at least one television signal.4 More than eight out of ten United States families actually have television sets, and 97 per cent of these television homes have a choice of two or more signals, while 79 per cent have a choice of four or more signals. The average television home has a choice of 5.4 different signals. ${ }^{5}$ As of August I, 1957, there were 477 commercial television stations actually in operation, ${ }^{6}$ all but a relative handful of which were affiliated with one or more of the three nationwide television networks. ${ }^{7}$

A further measure of the present dimensions of television and its rapid growth is the size of the advertisers' investment therein. From a volume of $\$ 57.8$ million in 1949 , advertising on television grew to more than $\$ 1,209.9$ million in 1956.8

The rapid growth and public acceptance of television is attributable mainly to the network organizations. They were active in the development of television long before most others now on the scene. Prior to World War II, the network organizations were experimenting with television, but full-scale commercial operation was not commenced until after the end of the war. At the outset, of course, there were few television receivers. Since advertisers were unwilling to pay for programs with

* A.B. 1935, LL.B. 1938, Harvard University. Vice President, Columbia Broadcasting System, Inc.; member of the New York bar.

+A.B. 1937, J.D. 1939, University of Michigan. Vice-President and General Attorney, CBS Telcvision, a division of Columbia Broadcasting System, Inc, member of the New York bar.

$\ddagger$ A.B. 1933, LL.B. I936, Harvard University. Assistant General Attorney, CBS Television, a division of Columbia Broadcasting System, Inc.; member of the Massachusetts and District of Columbia bars.

${ }^{2}$ CBS Television Research Department (September 1957).

${ }^{3} \mathrm{CBS}$, Inc., Economic Advisor Department.

${ }^{3}$ Nielsen Television Index, July r956-June r957.

"All non-television-owning families in counties where television ownership is at least $10 \%$ plus all families owning television sets. Advertistng Research foundation, National Survey op Television SETS IN U.S. HousEHOLDS (1956).

"Based on a special Nielsen Television Index study as of May I, r957.

${ }^{6}$ Broadcasting-Telecasting Magazine, Aug. 5, 1957, p. rog.

" At the present time, there are three regularly operating nationwide networks: American Broadcasting Company ( $\mathrm{ABC}$ ), a division of American Broadcasting-Paramount Theatres; CBS Telcvision, a division of Columbia Broadcasting System, Inc. (CBS); and National Broadcasting Company (NBC), a subsidiary of Radio Corporation of America.

${ }^{8}$ Printers Ink Magazine, Aug. 23, x956, p. 55, citing McCann-Erickson, Inc., estimate. 
such small potential audience, there were few programs. This, in turn, gave little incentive to the public to purchase television receivers.

The circle of economic frustration was broken by the network organizations. At enormous cost, they programmed far in excess of what was justified by the then current economics of the situation. They provided the major entertainment programs and broadcasts of popular sports events and important political events of national interest, despite a lack of sponsors for these programs. It was this investment of creative energy and dollars which gave television its major impetus, both as an entertainment and information medium and as an outlet for advertisers.

It was this investment, repeated year after year, which helped build the networks into the largest organizations in broadcasting today. Perhaps partly because of their size, some of their practices-the very means by which the present state of the television art has been attained-and the financial results of these practices have recently become the object of criticism from certain quarters and are now under the scrutiny of the administrative and legislative organs of the federal government.

It is the purpose of this article to consider the principal practices under attack. ${ }^{9}$ Their proper evaluation, however, requires an explanation of the functions of a television network, its place in the television scheme, and its relationship and responsibilities to the public, television stations, and advertisers. Limited by space considerations, it will be impossible to deal as comprehensively as we would like with the various aspects of the business of networking and its multi-faceted relationships. Nevertheless, an attempt will be made to outline networking in its major aspects so that the reader may approach the difficult task of assessing the charges against the networks armed with some understanding of the networking business.

\section{The Functions of a Network Organzation}

A television network is a number of television stations in different localities, each related by contract with an operating organization, pursuant to the terms of which it undertakes to and does broadcast programs originating from the operating organization. ${ }^{10}$ All or most of the stations on the network are physically interconnected-

\footnotetext{
'Much of the material presented herein is derived from a document entitled "Network PracticesMemorandum Supplementing Statement of Frank Stanton, President, Columbia Broadcasting System, Inc.," prepared for and submitted to the Senate Committee on Interstate and Foreign Commerce by Columbia Broadcasting System, Inc. in June, 1956. The "Opinion of Counsel and Memorandum Concerning the Applicability of the Antitrust Laws to the Television Broadcast Activities of Columbia Broadcasting System, Inc." submitted to the same committee by the firm of Cravath, Swaine, and Moore, New York City, is a thorough analysis of network practices which have been subject to criticism. Such analysis refutes charges that network practices may have been violative of the antitrust laws. Due to space limitations, we are unable to give any extended discussion of this subject. Running through the latter half of the article, however, is a brief discussion of the impact of the antitrust laws on the networks and their practices.

${ }^{10}$ This latter, i.e., ABC, CBS, or NBC, is more properly described as a "network organization" rather than as a "network," which refers to the group of stations carrying the programs emanating from the network organization. However, in accordance with common usage, these organizations will frequently be referred to herein as networks.
} 
either by telephone cables or microwave relays-so as to be capable of the simultaneous broadcast of the same television program. However, it is not unusual that one or more of the stations comprising the network will, by the use of film, broadcast or "carry" the program on a "delayed" basis, that is, at a later period than originally transmitted by the network organization.

While each of the television network organizations owns and operates a limited number of television broadcast stations, ${ }^{11}$ for the most part, a network is comprised of independently-owned and operated stations, each of which is linked with the network organization by a contract-termed an affiliation agreement-which defines their relationship and their mutual rights and obligations. The stations are frequently referred to as affliates of the network organization.

Each network provides a schedule of program $\mathrm{s}^{12}$ to its affiliates, arranging for the physical interconnection necessary to carry network programs to the stations for broadcast to the viewing public within their service areas. Thus, in a sense, the public is the ultimate recipient or beneficiary of these arrangements. ${ }^{13}$

To pay the costs of these network broadcasts and to provide revenues to pay program and other charges, as well as profits, of both the network organization and the stations, the network seeks to sell nationwide broadcast time and programs to national advertisers who, in return, are afforded the opportunity of broadcasting over the network commercial messages accompanying the programs. Thus, a network is a national advertising medium. Advertisers are the network's customers-the buyers of broadcast time and of programs offered by the network organization. Each affiliated station, in turn, supplies to the network one element of that servicelocal broadcast time over that station-and is paid by the network for the use of that time in accordance with the rate of payment agreed upon in the affiliation agreement.

Accordingly, it is clear that a network has vital links with three distinct groupsthe public, stations, and national advertisers.

\section{A. The Public}

Networks bring to the public news, information, education, and entertainmentall free of charge. Today, via the networks, the entire nation can see the Sadler's Wells Ballet, the World Series, Peter Pan, The Caine Mutiny Court-Martial, debates and discussions between and by the world's leading figures, and almost an infinite variety of the best available entertainment. Network television has brought about a stronger cohesion among the people of the United States and a greater first-hand knowledge of the entire country. And it makes available a means by which in times of national crisis the nation is afforded a means of immediate

\footnotetext{
${ }^{11}$ The maximum number of television stations which any person may own or operate is limited to 5 VHF stations and 2 UHF stations. FCC Rules and Regulations, 47 C.F.R. $\$ 3.636$ (Supp. 1956).

${ }^{23}$ These programs may be produced and owned solely by the network organization, produced in association with others and jointly-owned, or produced and owned entirely by outsiders. In addition, there are numerous subsidiary rights in the programs which may be held by any number of different interests.

${ }^{13}$ The practices, relationships, and functions herein described pertain only to the present system of so-called free television, wherein the public receives the programs with no direct charge to it.
} 
mobility. The only source of nationwide live programming is the networks. Only such live programming will permit events of national interest to be seen throughout the country as they happen. While film programs may be and frequently are good, it is its live quality which is the real magic of television. To remit television largely to film-not an unreal threat if the networks are throttled-would be seriously to confine the excitement, scope, and impact of television.

\section{B. The Stations}

In considering the functions performed by the network for its affiliated stations, it is important to bear in mind that, unlike radio today, the cost of television programming, even on a local basis, is very high. Accordingly, the furnishing of programs to the stations is an important function of the network organization. In addition to the fact that revenues accrue to the station for carrying the network programs, the station is relieved of the necessity of expending monies for its own local programs or for the acquisition of other outside programs. ${ }^{14}$ A basic by-product to the stations, which results from network programming ${ }^{15}$ is a large audience circulation. It is on this circulation that the station bases its advertising rate. Thus, increased circulation will attract additional revenues to the station both from national spot advertisers ${ }^{16}$ and from local advertisers. A basic fact of television advertising is that advertisers look to "adjacencies"-the times which may be available adjacent to the programs which have attracted the largest audiences.

\section{National Advertisers}

For national advertisers, network television provides large circulation at specific time periods in the schedule at a low unit "cost per thousand" and in one efficient purchase. An advertiser's investment in network television will not be made unless he is persuaded that he will receive sound value for his money. It is a network's function to organize itself and fashion its network line-up of stations and programming so that it can make network television a good buy. For advertising dollars are essential to television as we know it today.

Thus far, we have examined the broad dimensions of television and, in general, the services and functions which network organizations perform for the public, for stations, and for advertisers. Greater specificity and fuller understanding of the scope of these services and functions can be furnished by a brief outline of the structure and operations of a particular television network. ${ }^{17}$

\footnotetext{
1s The network schedule of programs supplied to its affiliates includes, in addition to those sponsored by advertisers, sustaining (i.e., unsponsored) and public-affairs programs.

${ }^{20}$ The rating services show that, with rare exceptions, network programs are the most popular.

${ }^{10}$ National spot advertisers are advertisers who elect to acquire and broadcast their programs on a "spot" basis in several markets. The programs are not necessarily broadcast at the same time in each market, the network is not utilized, and there is no interconnection.

${ }_{17}$ The CBS Television Network has been selected because of our familiarity with its internal workings. For the same reason, statistical and other data cited in this article will frequently relate specifically to CBS.
} 
D. The CBS Television Division

The CBS Television Network is a part of the CBS Television Division, one of the six operating divisions of the Columbia Broadcasting System, Inc. ${ }^{18}$ In addition to operating the network, the CBS Television Division operates VHF television stations in New York, Chicago, and Los Angeles and UHF television stations in Milwaukee and Hartford. ${ }^{19}$ The Division also includes CBS Television Spot Sales, an organization which acts as national spot advertising representative for the CBS owned stations and for eight CBS Television affliates. CBS Television Film Sales, Inc, a wholly-owned subsidiary of CBS, syndicates entertainment and newsfilm programs to television stations, regardless of network affiliation, and to national advertisers who place such programs on a spot basis with television stations.

\section{The CBS Television Network organization and staff}

Organizationally, the CBS Television Network comprises 47 major operating units, divided into five main groups: (I) Programming; (2) Sales; (3) Operations; (4) Operating Services, including Station Relations, Engineering, and Research; and (5) Administrative Services. The weekly cost to CBS Television of maintaining this organization and staff is about $\$ 700,000$. In 1949 , the full-time personnel devoted to the television network numbered only 427; in contrast, as of March r, 1956, CBS Television employed on a full-time basis 2,412 people for its network and a total of 5,493 people, including per diem personnel, talent, and supporting corporate personnel. ${ }^{20}$

\section{CBS Television Network physical facilities}

In order to supply high-quality programs to its affiliates day in and day out, a television network must provide and maintain elaborate physical facilities. The CBS Television Network now has $3 \mathrm{I}$ broadcast studios-22 in New York, five in Hollywood, and four in Chicago. Except for five in New York, all are equipped for the production of live programs. CBS has invested nearly $\$ 28$ million in its television network program production facilities in New York and Hollywood alone.

\section{The CBS Television Network affiliates}

The CBS Television Network includes the aggregate of stations affiliated with CBS Television. As noted, only five of these stations are owned by CBS. The

${ }^{18}$ The other five operating divisions are: the CBS Radio Division, which operates the CBS Radio Network and six radio stations; the CBS Laboratories Division, which is engaged in research in electronics and other fields; the Columbia Records Division, which produces primarily phonographs and records; the CBS-Hytron Division, which manufactures electronic tubes; and the CBS International Division, which is engaged in the export business.

${ }_{10}$ The Federal Communications Commission has recently awarded a Construction Permit to CBS for a VHF station in St. Louis.

${ }^{20}$ Included in the last category are personnel in the CBS News and Public Affairs Department, maintained by CBS in order to fulfill its responsibility as a medium of mass communication devoted not only to entertaining, but also to informing the people. The 1956 gross annual operating budget for the CBS News and Public Affairs Department was $\$ 7,000,000$. It services both the CBS Television and the CBS Radio Division. 
remainder are wholly owned by others. In total, as of September I, I957, the CBS Television Network furnished programs to 189 affiliated stations in the United States, 30 in Canada, and nine in Alaska, Hawaii, Agana, Guam, M.I., Mexico, Cuba, and Puerto Rico. Of these, I93 were primary affiliates and 35 secondary affiliates. ${ }^{21}$ As of September I, I957, CBS Television affiliates reached 40,485,300 families in the United States, or 99.18 per cent of all the families who own television sets.

\section{AT\&T interconnection facilities}

In addition to its own organization and the facilities which it must maintain, a network must arrange for a means by which its affiliates throughout the country can be interconnected in order to serve its affiliates with its program product. ${ }^{22}$ Only in this way can a program be seen simultaneously by viewers on a nationwide basis. Interconnection is, of course, necessary for all live programs, whether they be entertainment programs or broadcasts of public events as they occur. Even with respect to film programs, interconnection is necessary in order to provide simultaneity and to make it possible for an advertiser to have his program and his advertising continuity broadcast through a single purchase from a single source and at a fixed point in the network program schedule.

At present, most network stations are interconnected by American Telephone and Telegraph facilities, either in the form of coaxial cables or microwave relays. These facilities are used by the networks on a continuous basis and represent a major expense to the networks. CBS Television, alone, is currently paying at the rate of $\$ I_{4}$ million a year to the AT\&T for the use of interconnecting facilities. ${ }^{23}$

\section{The CBS Television Network program schedule}

The end result of the CBS Television Network staff, physical facilities, and aggregate of affiliates is the CBS Television Network program schedule. It is a truism that television is a voracious consumer of programs. A network must produce a full day's schedule day in and day out, and it cannot leave the screen blank even for a minute once a program is scheduled. Some idea of the dimensions of the task of a network can be gained from the following example. During the week ending April 7, 1956, the CBS Television Network furnished to its affliates 129 live programs, varying in length from 15 minutes to three hours and covering an aggregate of $683 / 4$ broadcast hours. Including both live and film programs, the total was $861 / 4$

21 The terms "primary affiliate" and "secondary affiliate" are convenient means of loose classification of affiliates and are not subject to precise definition. Generally speaking, the principal difference between a primary affiliate and a secondary affliate is that the affiliation agreement with a primary affiliate provides for network option time, while the affiliation agreement with a secondary affiliate does not.

${ }^{23}$ Of 189 United States CBS Television affiliates, 178 are interconnected. The II noninterconnected affiliates are dependent on television recordings which are supplied by the network organization.

${ }^{23}$ If interconnection facilities were not supported by the networks' regular and substantial use, and if instead they were used only on special occasions such as the World Series or a political convention, their costs on such an occasional use basis would vastly increase-possibly by as much as 30 or 40 times per program. And it is likely that if these interconnection facilities were used only occasionally, at least those which go to the smaller markets outside the top 40 or 50 cities would not bo used with sufficient frequency to warrant their being preserved by AT\&T for television use at all. 
hours. It is estimated that in 1956 , the program product of the CBS Television Network alone, in terms of hours, was more than three times that of the total product of feature films released from Hollywood in 1955 , and that of CBS Television and CBS Television in association with outside sources was six times that of feature films from Hollywood.

The Economics of Networking

There are two facets to the economics of the network's operations. One deals with the distribution of the revenues accruing to the network. The other arises out of the relationship between network broadcasting and the advertiser. A discussion of these two aspects of networking economics will help to bring into sharper focus the functions and multiple role of the network organization.

\section{A. Revenues of Networking and Their Distribution}

The charge to an advertiser for a program broadcast over the network and sponsored by the advertiser involves two elements-program charges and time charges. Program charges are intended to recoup the cost of creating and producing the program. They are payable to the network only when the program is sold by the network to the advertiser. Where it is produced and sold by outside producers, the program charge is made by the outside producer.

Time charges are applicable in the case of all sponsored programs-regardless of their sources-broadcast by the network. The time charge to an advertiser is the aggregate of the rates-usually' published in the form of a network "rate card"-of each of the stations on the network carrying the program. This charge is known as the gross time charge. Discounts are usually allowed advertisers in order to encourage (I) their use of the maximum number of stations and thus assist the stations in the smaller markets to obtain network programs and to maximize service to the publicand (2) week-to-week continuity in advertiser sponsorship by making it more economical for advertisers to support major programming throughout the year. The time charge remaining after these discounts is known as the net time charge. From this amount, the network also pays the advertising agency's commission-15 per cent of the net time charge.

One further expense-and a major one-which must be paid out of the time charge is the cost of physically bringing the program to each of the affiliates which carries it. This cost of distribution includes a share of the network's payments to $A T \& T$ which represents the approximate cost for the use of $A T \& T$ transmission lines allocated to the program. The network also pays for the television recordings where the AT\&T facilities are not available to or used by the stations.

The time charge revenues thus remaining to the network are further reduced by the payment to the affliates for the station time devoted to the program. In this connection, it is important to note that the affiliation contracts normally provide 
for payment to the stations of a percentage of the gross time charges to the advertiser. As shown, this gross amount is not received by the network; it is reduced by several direct major deductions and expenditures. Thus, in fact, the percentage paid to the station, when related to the amount retained by the network, is much greater than that specified in the affiliation agreement. ${ }^{24}$

To illustrate this flow of revenue, a typical case is cited-Climax, an hour-long dramatic series broadcast by the CBS Television Network and sponsored by the Chrysler Corporation.

The average gross weekly charges to the advertiser for Climax during January, February and March I956 totalled $\$ 37,007$. Of this, $\$ 43,287$ constituted program charges and $\$ 93,720$ time charges.

Fifteen per cent of the $\$ 43,287$ program charges, or $\$ 6,493$, was paid to Chrysler's advertising agency as the customary agency commission. There remained to the CBS Television Network $\$ 36,794$ to apply against the costs which the network incurred for the program. Those costs fall into two general categories: (I) the costs of creating the program each week, known as "above-the-line costs," and (2) program production and (studio and technical) facilities costs, known as "below-the-line costs." The direct above-the-line costs for Climax averaged \$26,065 weeklysalaries to 59 people who devoted an average of 2,454 man-hours to each week's programs. The direct below-the-line costs for production and facilities averaged a total of $\$ 19,451$ a week, including salaries to 263 additional people who spent an average of 2,I05 man-hours per program. Thus, although Chrysler paid $\$ 43,287$ per week for program charges for Climax, the actual amounts expended by CBS Television directly for the program totalled $\$ 52,009$. $^{25}$

The advertiser's discounts in connection with Climax aggregated $\$ 23, \mathrm{I} 75$, resulting in a reduction of the net time charges to $\$ 70,545$. After deducting the 15 per cent agency commission on this amount, there remained to the network $\$ 59,963$ as revenue from the time charges for the 164 stations carrying the program. From this amount, $\$ 6,056$ was paid to AT\&T for line charges and $\$ 1,259$ weekly for television recordings.

Of the $\$ 52,648$ time charges remaining, $\$ 26,185^{26}$ was paid each week to the affiliates carrying the program. This is almost equal to the amount ultimately retained by CBS Television after all deductions, payments and charges, but without taking into account the $\$ 8,722$ deficit incurred by CBS Television in the production of the program.

To determine whether such a division of revenues between stations and the network is equitable, the functions of each should be examined. The station provides

ac The CBS Television Network affiliation agreement usually provides for payment to the station of $30 \%$ of its gross rate.

${ }_{25}$ In one sense, the program is not typical: the amount by which the program costs exceed program payments by the sponsor was abnormally large. But some loss is not unusual. The loss here, and in connection with other programs, is the price paid by the network to develop and maintain a strong over-all program schedule for the public, station affiliates, and advertisers.

${ }^{20}$ Exclusive of $\$ 940$ deducted for music license payments to BMI and ASCAP. 
the use of its transmitter and the most valued commodity which it has to offer-its time. In providing its transmitter and time, the station must, of course, attribute to that time a proportionate share of its investment and of the costs of its over-all operations. But the actual out-of-pocket expenses attributable to the network program are normally minimal. ${ }^{27}$ And, in turn, the personnel of the station are thus freed to create local programming, to sell the station's own (or outside produced) nonnetwork programs to national spot and local advertisers, and to do all the things necessary for successful local operation. As has been shown, in addition to receiving a share of the network revenues and saving those costs which would be incurred if the station were required to program that period itself, the station benefits from the increased circulation which enables it to charge substantial rates and to attract national spot and local advertising revenues directly.

On the other hand, the network must pay for the network staff and facilities, ${ }^{28}$ and for all the functions and services which it must render out of the net residue of time charges accruing to it. It must maintain its organization and its over-all programming schedule, including all its sustaining and public-service programs.

The network organization is large and complex. It must be maintained in order to provide the highest quality programs possible, integrated into a balanced over-all weekly schedule of entertainment and information. Such a schedule requires an organization of the best creative personnel obtainable-executive and talent, writers and performers. Also, there are enormous risks which must be taken through entering into the long term contracts and expensive commitments necessary to attract creative skills. Not all risks culminate in success. Some of the projects in which tens of thousands or hundreds of thousands of dollars are invested have to be abandoned; programs in which the network organization has made large investments in energy and dollars sometimes have failed even to get on the air.

It is important to bear in mind that when a network fails to make a time sale to an advertiser it not only loses the revenues; in addition, its costs are vastly increased as it continues its network service. Its program service to its affiliates cannot, in general, expand and contract in direct proportion to advertisers' time purchases but must continue at the same pace regardless of whether time and program revenues are forthcoming. Thus, even though a time sale is lost, a network organization must, as a rule, maintain its program service to its affliates-maintain it at a high qualita-

${ }^{97}$ In some instances, a network advertiser may order an additional station at least partially through the sales efforts of the station itself, whose representative may go directly to the advertiser's agency to persuade it to add the station to the lineup. These activities, supplementary to the network's own efforts to sell the station, do involve special expenses to the station attributable to the network program. And, although AT\&T costs are normally assumed by the network organization, there are cases in which stations assume incremental expense.

${ }^{28}$ Only some staff and facilities expenses are paid for out of the program charges. The unreimbursed portion of these expenses must be paid for out of the residue of the time charges. Still another unreimbursed expense arises when nonsponsored (sustaining) programs are broadcast by the network. The residue of time charges is the only source for covering staff, facilities, and other expenses attributable to sustaining programs. 
tive level-if an over-all effective network program schedule on behalf of its affiliates, other advertisers, and the public is to be continued.

Failure to sell one hour between 7:30 and ro:30 PM each night for a year (whether because of refusal of stations to clear time or for any other reason) would result in an enormous swing in a network's profit and loss figure. In the case of CBS Television, the net revenues (net time charges less station payments) that would have been lost from the failure to sell one night time hour each broadcasting day throughout 1955 would have been $\$ 13$ million. In addition, the expenses to provide sustaining programs of comparable quality for the period would have been increased by some $\$ 13$ million to \$I million. Thus, the loss of the sale of one such hour for the year could have adversely affected its balance sheet by an amount in excess of $\$ 26$ million.

\section{B. Advertiser Economics}

A television network must produce sound economic values for advertisers. The networks compete for national advertisers' dollars not only with the other television networks, but with national spot television advertising, with newspapers, magazines, radio, direct mail, trade publications, outdoor advertising, and with such miscellaneous forms of advertising as car cards and match boxes. ${ }^{29}$

It is this factor of competition with other national advertising media which is a major touchstone of network economics. The competition between media is intense and direct. Such competition is an added reason why there must be a constant and persistent effort by television networks to keep absolute, as well as relative, costs at a minimum.

Any factor which adversely affects the economic value of television for the advertiser almost inevitably results in less money for the medium. And this, in turn, normally means more restricted programming in terms of both quantity and quality. Necessarily, therefore, in organizing its network of stations and in creating its programming structure, a network organization must strive to provide a medium which has the maximum possible economic value for advertisers. When an advertiser decides whether to spend his money for a program to be broadcast on the CBS Television Network, or for a television program on another network, or for another medium altogether, probably the most important factor which influences his decision is which medium (or program) will produce the greatest sales per dollar spent. Or putting it another way, the advertiser's question is which medium costs least per unit of sales produced. This depends on three factors: the cost of the medium, the number of homes reached by the medium, and the "impact" of the medium (i.e., the effectiveness of the medium in producing sales in the homes reached). In order to determine whether the cost is justified, the advertiser must relate the cost to the number of homes reached by the program and to the "impact" of the program.

\footnotetext{
${ }^{20}$ Of the entire broadcasting share of national advertisers' budget, the share accruing to ( $\mathrm{I}$ ) network television, (2) network radio, (3) national spot television, and (4) national spot radio, amounts to less than 20 per cent of the total national advertising expenditures. Thus, less than one out of every five dollars spent by national advertisers is spent on the broadcasting media.
} 
Before a program goes on the air, there is no way an advertiser can be certain of how many homes the program will reach. However, the number of homes the program will reach obviously depends to a large extent on the potential audience of the program-the number of television families living in the areas served by the network affiliates which the advertiser orders. The number of such families served by each of those affiliates is commonly referred to as the station's "circulation." A station's time rate, divided by its circulation (in terms of thousands of families), gives its cost per thousand circulation-a figure which is television's counterpart of a newspaper's or magazine's cost per thousand circulation and is used generally in the advertising field to compare the circulation costs of different advertising media.

The usual method of estimating homes actually reached by a program (as contrasted to circulation of the stations carrying the program) is conducting national sample surveys. Since these surveys are much too expensive for an individual or company to perform solely for its own information, the surveys are made by organizations known as "rating services," and the results are syndicated to many subscribers.

Measuring "impact" or sales produced per home reached is much less precise than measuring the number of homes reached by a a program. Sometimes it is intuitively evaluated by the advertiser. However, just as the format of a magazine and the position and attractiveness of the advertisement carrying the sponsor's message influences. "impact" in a magazine or newspaper, so also do the nature of the television network of stations, the particular program he sponsors, the attractiveness of the commercial he presents, and the quality of the programs adjacent to his determine the impact of the sponsor's television program. Homes reached by the program plus the impact of the program when related to the cost of the program will generally determine whether an advertiser will use television or another medium.

Since cost per thousand circulation for a television program (or any medium) is so important in determining cost per sale produced by the program, it is for most advertisers a major factor ${ }^{30}$ in determining whether to use the program as an advertising medium. An advertiser will not ordinarily pay twice for the same unit of circulation because the audience will not be proportionately enlarged and each viewer can only look once at any given time. A network's choice of affiliates, accordingly, must be based on a pattern whereby each contributes the maximum additional unduplicated service.

Within the framework dictated by advertiser economics, the networks have also adopted a policy of affiliating with stations in smaller markets in order to extend network program service into areas which would otherwise not be served. ${ }^{31}$ The CBS Television Network has succeeded in providing nationwide service, reaching all but

\footnotetext{
${ }^{30}$ In some cases, an advertiser may be interested in advertising for prestige purposes or to deliver a message to a special audience. In such cases, cost per thousand (or even cost per sale) becomes less important.

${ }^{81}$ As of September I, 1957, the CBS Television Network had affiliated with 32 television stations, each of which covers less than.40,000 television families. The smallest of these is KGEZ-TV, Kalispell, Montana, with a September I, I957 circulation of only 5,200 television homes.
} 
eight-tenths of one per cent of the television homes, and at the same time keeping cost per thousand at a reasonable level by the adoption of two plans. They illustrate some of the potentialities, as well as the limitations, of increasing service to stations and the public without violating the basic economics of television networking.

\section{The Extended Market Plan (EMP)}

This plan was devised to encourage advertisers to use stations in smaller markets. Because there are actual out-of-pocket operating expenses for AT\&T lines and for the other functions which a network must perform in servicing stations, a minimum volume of orders for a station is necessary to avoid network losses attributable to the station. Based on experience, CBS Television had found that stations with a gross hourly night time rate of less than $\$ 150$ usually result in a net operating loss for the network, since the network's share of any lesser rate normally does not permit service to such an affiliate at a profit to the network. Hence, the minimum network rate for any station had been fixed at that figure. As a result of this rule, markets served by stations which had lower rates were not provided with CBS Television Network service or, alternatively, if the station did maintain a rate of \$150 where its circulation did not warrant it, advertiser orders for such stations were sparse. In either event, the public served by such stations in smaller markets was deprived of network programs, and the stations received neither programming nor revenuesboth of particular importance to the smaller stations.

The EMP cut through this dilemma by abandoning the rule of the $\$ 15^{\circ}$ minimum rate. By agreement with the stations, lower rates-in some cases as low as $\$ 50-$ related to their actual circulations were established. To induce the advertiser to use the stations in sufficient volume to cover the network's out-of-pocket expenses, and to provide the stations with revenues and programs, a special network sales unit was assigned to work exclusively on obtaining orders for EMP stations. In addition, the network provided special discounts, in addition to the regular discounts, to an advertiser ordering EMP stations. ${ }^{32}$

As a result, from the date when the EMP was instituted to September I, I957, the number of regular CBS Television advertisers using the plan had increased from $3^{\circ}$ to 46 , and the number of EMP stations on the air in the United States had increased from ${ }^{3} 3$ to $3^{\mathrm{I}^{33}}$ (six of which are UHF stations). In approximately two and onehalf years, television receiver ownership in the markets covered by these stations had increased from 143,000 to $1,017,700$. Because of the increase in circulation, 14 EMP stations were able to increase their network rates by an average of 46 per cent. Yet, in spite of those rate increases, the cost per thousand has dropped from $\$ 5.52$ to $\$ 2.32$, and the average network payment to each EMP station is about $\$$ r,03I a month. ${ }^{34}$

${ }^{32}$ It is to be noted that those discounts do not reduce the revenues to the station. Since the station's percentage is based on gross rate before reduction for discounts, the entire cost of the discounts is borne by CBS Television.

${ }^{83}$ Two additional EMP stations are located in Juneau, Alaska, and Agana, Guam, M. I.

${ }^{34}$ For the four-week period ending July 27, 1957, the gross time billing for all programs carried on Extended Market Plan stations was \$ro6,825. 


\section{The Extended Program Service Plan (EPS)}

This plan was designed to extend program service to the smaller markets. It represents an attempt to encourage the distribution of sponsored programs to affiliates which are not ordered by advertisers. In accordance with that plan, CBS Television offers commercial programs to many of its regular affiliates which are not ordered by advertisers. Although the stations receiving EPS programs may not carry the commercial messages and are not permitted to insert substitute commercials into the programs, they are able to sell spot announcements both before and after the programs. CBS Television thus provides those stations with the drawing power of network programs and thereby increases the value of the adjacencies available to be sold locally or to national spot advertisers. Additionally, the stations do not have to program locally to fill the time. The public, of course, benefits from the plan by the increased availability of high quality programs. The plan has been partially successful: in September, 1957, under the plan, ro 7 CBS Television Network affiliates received one or more of 39 network commercial programs.

Its limited success is illustrative of the necessity of adapting affiliation practices and program service to advertiser economics. In order for a program to qualify for inclusion under EPS, permission must be obtained from a number of different sources, each of which has a legitimate interest in the program. Thus, for example, it is necessary to obtain permission from the advertiser who is paying for the program. It is hardly to his interest to permit the program, with commercials deleted, to be carried on a station whose circulation significantly duplicates the circulation for which the advertiser pays. To require the advertiser to permit the program to be carried without commercials on a duplicating station would be to require him to compete with himself. Understandably, some advertisers have been reluctant to permit inclusion of their programs on a station which duplicates the coverage of a station for which he pays.

Similarly, the rights of the program producer and talent, as well as the syndication rights, if any, must be taken into account. Where a filmed program is involved, for example, the owner of the program may be reluctant to permit it to be carried in unordered markets free and thus diminish the possibility of future sale to stations in those markets. ${ }^{35}$

In addition to providing an efficient aggregate of network stations, it is necessary, in order to furnish the advertiser with maximum network values, to provide an effective over-all weekly network schedule. It is the network's special obligation, both to the public and to advertisers, to provide: (I) a suitable number of popular programs well-balanced as to type between information and entertainment both for purposes of variety and in order to serve the public interest; and (2) assuming that strong and balanced programs are provided, a schedule in which these programs are placed in such reference to each other as to maximize their over-all appeal.

ss Where all the program rights, however, reside in CBS Television or the syndication rights belong to CBS Television Film Sales, Inc., consent for inclusion of the program in EPS is granted. 
These objectives are important not only to the stations and to the public; they are also important to advertisers. Both the over-all schedule and the program which precedes and which follows the time period which an advertiser has under consideration are important to him, for he knows that audiences are built up and retained through an appropriate flow in sequence of programming. ${ }^{36}$

\section{III}

\section{The Reasonableness of Network Practices}

It is appropriate now to examine various network practices and some of the criticisms which have been made against the networks. ${ }^{37}$

\section{A. Television Network Revenues and Monopoly}

It has been charged that the networks receive a disproportionately large share of television revenues. The facts already described concerning the economics of networking and the distribution of revenues between stations and the networks are ample refutation of this charge. In fact, station profits in terms of percentage of return on total broadcasting revenues (i.e., sales) far exceed network profits in percentage of return, despite the sharply contrasting functions of networks and stations and the relative risks which each takes. ${ }^{38}$ As has been pointed out, in order to perform its functions at all, a network must maintain a large organization and extensive facilities. Necessarily, therefore, the very nature of its functions is such that its revenues are large; but for the same reason, its expenses are also proportionately large.

In network operations, there are double risks and liabilities. The loss of a sponsor for a program period entails not only the loss of revenues but an additional heavy burden of uncompensated expense in providing a program service to the stations on a sustaining basis. A station's operations do not normally entail a like risk. While

30 "Audience flow" does not mean that a poor program has a larger audience than it deserves because it follows a popular program. Rather, it means that a program is not deprived of the audience it deserves by following a poor program. People will not watch a poor program no matter how much they like the program that preceded it. However, when two or more good programs are presented at the same hour over different stations in the same area, a large part of the audience of one station may never know that a good program is on the other station if their attention has already been attracted to the first station by a preceding program on that station which they enjoyed watching.

${ }^{37}$ These criticism have come from several sources. In the main, those considered here are suggested or contained in one or more of the following: Senate Committee on Interstate and Foreign Commerce, Television Network Regulation and the UHF Problem, 84th Cong., Ist Sess. (1955); Senate Committee on Interstate and Foreign Commerce, Investigation of Television Networks and the UHFVHF Problem, 84th Cong., Ist Sess. (1955); statement and testimony of Richard A. Moore, President, KTTV, Inc., Los Angeles, Cal., in Hearings Before the Senate Committee on Interstate and Foreign Commerce on the Television Inquiry, 84th Cong., $2 \mathrm{~d}$ Sess., pt. 4, at 1475-518 (I956); Senate Committee on Interstate and Forcign Commerce, The Network Monopoly, 84th Cong., 2d Sess. (1956); House Committec on the Judiciary, Report of the Antitrust Subcommittee on the Television Broadcasting Industry, H. REP. No. 607, 85th Cong., Ist Sess. (1957); Senate Committee on Interstate and Foreign Commerce, Television Network Practices, 85th Cong., Ist Sess. (1957).

${ }^{88}$ According to calculations based on FCC, Television Broadcast Financial Data for 1955, the pretax rate of return on sales for all networks combined was $12.1 \%$ in 1955 , while the comparable figure for 421 independent stations was $22.2 \%$. 
it is true that a station loses its share of the revenues when a network program loses its sponsorship, the station still has the opportunity of selling the time period to a national spot or local advertiser. And failing that, it receives the network sustaining program at no progamming cost to it for that period. In contrast, the network organization must bear the full expense of the sustaining program. Its cost is paid for out of the network organization's share of the revenues from sponsored programs.

In the circumstances, the comparison frequently made of the total revenues of the stations and the total revenues of the network has no meaning. Their contrasting functions should be taken into account. A more reasonable basis of comparison would be the relative percentage of profits in their relation to revenues. On such basis, no disproportion in favor of the network exists.

The charge has been made that the two leading networks, CBS and NBC, constitute monopolies. At the threshold of any discussion of this charge, one vital fact must be recognized. Each network must be considered separately. There has been no suggestion that there is any combination, conspiracy or joint action of any kind among the networks in any of the markets. In fact, there is intense competition among the networks. ${ }^{30}$ Each is engaged in trying to take audience, programs, talent, advertisers, and affliates from the other. This intense competition has benefited the public in terms of programs and service they have received.

Neither in fact nor in law does a monopoly exist. As has been shown, there are many other national advertising media in competition with network television. Network television received only a 9.8 per cent share of the national advertising dollar in 1955. The CBS Television Division-the network and the stations owned by CBS -received only 3.2 per cent of the national advertising dollar and about 20 per cent of the television advertising dollar. Even if the relevant market for determining the existence of a monopoly be considered something less than the national market or the television segment of the national advertising market, the same result follows.

No network has dominance in the television network business. The gross billings of the CBS Television Network during 1956 totalled 45.8 per cent of the total network billings; of NBC, 38.5 per cent; and of $A B C$, 15.7 per cent. One of the phenomena of recent years in the television network field has been the growth of $A B C$, whose gross billing more than tripled from 1953 to 1956 . This hardly supports a charge of squeezing out the smaller network competitors, one of the indicia of monopoly..$^{0}$

${ }^{30}$ Thus, there is a significant difference between the situation presented by the television industry and that in United States v. Paramount Pictures, 334 U.S. I3I (1947), a casc often cited by critics of the networks. There, the major motion picture companies were found to have combined and conspired to restrain trade and competition, which in the court's view justified lumping them together for the purpose of applying the usual tests of monopoly.

10 The fact that there are only three regularly operating national networks is not evidence of monopolistic restraint. It results from the lack of available comparable station facilities and from the economics of network broadcasting. At the present time, there are not enough stations in cnough localities to support more than three regularly operating national networks. Neither network practices nor FCC regulations prevent the formation of new networks, national, regional, or part-time. In fact, under FCC regulations, no station may contract with a network so as to close itself to other networks. 
The growth of national spot television has also been large and is continuing. The competition between it and network advertising is strong. In the second quarter of 1956,49 per cent of total time expenditures for national television advertising consisted of time charges paid directly to individual stations on a national spot basis. Advertisers use both national spot and network advertising. They shift their efforts between the two from time to time, depending on their conclusions as to the competitive advantages and utility of each for their needs. The networks do not monopolize this segment of the market.

Basically, the charge of monopoly appears to be primarily an attack on size. But as has been shown, the very nature of the functions of a nationwide network requires substantial investments and commitments, extensive facilities, and staff. This necessarily entails a large unit. A nationwide network cannot be small if it is to perform network functions. Mere size, particularly where so shaped by the inherent requirements of the business, does not justify a charge of monopoly or monopolization.

\section{B. The "Must Buy" Practice}

CBS Television, in accordance with a long standing practice in the broadcasting industry, ${ }^{41}$ had, as of September, $\mathbf{1 9 5 7}$, a list of 57 affliates which it designated as "basic required" stations. Those stations cover substantially all the major markets in the United States and $87.3 \%$ of American television homes. With a few exceptions arising out of special circumstances and the special needs of network advertisers, the effect of the basic required list is to require advertisers who wish to use the network to order these stations as a minimum. ${ }^{42}$ The complaint against this practice is directed not against the minimum-dollar-purchase requirement, but against the designation of the specific stations to be purchased.

The basic required stations, taken as a group, constitute the indivisible product that CBS Television creates, assembles, and sells to its customer, the advertiser. They are the basic network. Combined, they provide a national advertising medium as distinguished from a local medium. The function of the basic network is to provide nationwide circulation in the television field, just as Life and The Saturday Evening Post serve the entire nation in the publication field.

The size and characteristics of the network medium are determined by CBS Television, based upon the interrelated requirements of its customers (advertisers), its affiliates, and its own internal economics. ${ }^{43}$ The minimum dimensions of the network having been outlined by advertiser demand, CBS Television has fashioned its product and geared its operations to meet that demand. Its purpose and function are merely to define and delineate the product that the network has for sale.

"1 Each of the networks has some form of must-buy or minimum purchase. ABC's differs from that of CBS and NBC in that it now requires only a dollar minimum purchase.

" 2 Except in the case of one station, there is no agreement between the CBS Television Network and the stations involved by which they are designated as "basic required." With this exception, CBS Television is free to, and does, alter the list as the economics of the situation requires.

${ }^{43}$ In practice, national advertisers who want network coverage almost universally order far in excess of the basic required stations. 
The basic required list was not adopted to suppress competition in any way and it does not have that effect. Advertisers have a great freedom of choice in the market. They have three different nationwide networks from which to choose. If they prefer not to use a network, they can choose on a spot basis any line-up of stations that they want, including network affiliates in the basic required group. Or they can, as many do, mix network advertising with spot advertising. Or they can choose nontelevision media, as some do. An advertiser should not be permitted, however, to choose a particular network and at the same time reject a substantial part of it, thereby making the rejected part unusable as a network for that period.

There are compelling economic reasons for prohibiting fragmentation of the network product. The network, as stated, makes heavy commitments for AT\&T interconnection service among its affiliates, on a minimum basis of eight hours per day. The cost of maintaining the interconnection service simply could not be supported by orders for only a few major stations. If an advertiser were to place an order, for example, limited to New York, Chicago, and Los Angeles, the costs for interconnection facilities, alone, would be unbearably excessive. There must be stations along the line to provide sufficient revenues to defray the cost. The extensive network services that have been described previously require the broad financial support of sales of the combined time of the major network affiliates. Those services cannot be supported by sales of only a small fraction of a network.

In summary, the basic required practice is a reasonable one. It is no more than a conformance to the normal demand of national network advertisers, and it is no different from any other minimum-order policy which a supplier adopts where the nature of his product, the requirements of his customers, and the economics of distribution justify it.

The charge has been made that the sale of time under these circumstances violates the antitrust laws in that it constitutes either an illegal tie-in sale or a refusal to sell, which, it is claimed, is illegal per se.

A "tying" arrangement involves both a "tying" product or service and a "tied" product or service. To acquire one product or service which the purchaser wants, he must purchase or acquire another distinct product or service which, in fact, he does not want. The basic-required practice, as hereinabove described, does not fit this description. Different or distinct elements are not tied-in. The network sells to its customer a single nationwide advertising service. This distinction was recognized by the Supreme Court in Times-Picayune Publishing Co. v. United States.44 There, a publisher of a morning and evening newspaper refused to sell advertising space in one unless space was purchased in the other. The Court held, inter alia, that the tie-in rule was not applicable since there was involved essentially the sale of but one item-"readership" in the market-rather than separate items. So, here, there is a sale of but one item, "listenership" in the national television market. In the

“ 345 U.S. 594 (1953). 
words of the Court in that case, it is the sale of a quantity of "fungible customer potential."

That the basic-required practice is not otherwise an unreasonable restraint of trade under section one of the Sherman Act, has been amply demonstrated. It is a reasonable business practice geared to the needs of both the networks and the advertisers. In effect, it but defines the network. Unreasonable restraint is neither its object or effect. The practice stems purely from business requirements and fails to evidence any purpose to monopolize. As has been shown, the percentage of the business or market controlled by each of the networks is insufficient to warrant any such inference. $^{45}$

In order to escape that inevitable conclusion, it has been urged that the refusal to sell is not an individual refusal on the part of the network but is a group refusal to sell, and hence illegal per se. The alleged group is the network and its basic required affiliates. As has been pointed out, the basic required list was established by and is maintained by the CBS Television Network without any agreement with its affiliates. There is in fact no concerted or group action. And, although it is sometimes loosely said that all group refusals to sell are illegal per se, the courts have never so held. Such group action is illegal only where it is a concerted refusal intentionally designed to affect competitors unreasonably or which actually results in unreasonable restraints on competition. ${ }^{46}$ Such is not the case here:

\section{Criticisms}

\section{Option Time}

The nature of the criticisms leveled at the option-time practices of the networks indicates that the reach and operation of option time may not be clearly understood. It is essential, therefore, to set out its precise nature at the threshold. To facilitate discussion, the standard option-time clause in CBS Television Network affiliation agreements is printed in the margin. ${ }^{47}$

${ }^{45}$ Cf. Times-Picayune Publishing Co. v. United States, supra.

10 Fashion Originators Guild of America v. FCC, 312 U.S. 457 (194I).

47 "(a) Station, as an independent contractor, will accept and broadcast all network sponsored programs offered and furnished to it by CBS Television during network option time (as hereinafter defined); provided, however, that Station shall be under no obligation to accept or broadcast any such network sponsored program (i) on less than 56 days' notice, or (ii) for broadcasting during a period in which Station is obligated by contract to broadcast a program of another network. Station may, of course, at its election, accept and broadcast network sponsored programs which CBS Television may offer within hours other than network option time.

"(b) As used herein, the term 'network option time' shall mean the following hours:

(i) if Station is in the Eastern or Central Time Zone, Daily, including Sunday, ro:00 A.M. to r:00 P.M., 2:00 P.M. to 5:00 P.M. and 7:30 P.M. to I0:30 P.M. (expressed in New York time current on the date of broadcast);

(ii) if Station is in the Mountain or Pacific Time Zone, Daily, including Sunday, 10:00 A.M. to I:00 P.M., 2:00 P.M. to 5:00 P.M. and 7:30 P.M. to I0:30 P.M. (expressed in local time of Station current on the date of broadcast);

"Nothing herein shall be construed (i) with respect to network programs offered pursuant hereto, to prevent or hinder Station from rejecting or refusing network programs which Station reasonably believes to be unsatisfactory or unsuitable, or (ii) with respect to network programs so offered or already contracted for, (A) to prevent Station from rejecting or refusing any program which, in its opinion, is 
Under the standard option-time provision, the network obtains an option on the affliates' broadcast time for the period covered by the option: three hours each during the morning, afternoon and evening periods. Thus, during the hours specified, the network has first call on the station's time for the placing of sponsored programs, subject to certain conditions and limitations. These conditions and limitations are highly significant. They were imposed by regulation of the Federal Communications Commission ${ }^{48}$ after an exhaustive study (in the radio field) of the effect on the industry and on the public of unrestricted options and after determination that the utilization of the limited option would, in the light of the importance of preserving the network function, be in the public interest and would not unduly adversely affect other segments of the industry. ${ }^{49}$ Thus, option-time is not, as has been suggested, "given" by the Government. It is, rather, not forbidden by the Government if suitably restricted. In each case, it is voluntarily arrived at by the network and the station as in the best interests of each.

As stated, the limitations on the reach of option time are important. It is inapplicable as against programs of any other network. It may not be exercised by a network on less than $5^{6}$ days' notice. In addition, it is sharply limited so as to permit broad discretion by the station. As the option clause provides, a station has the right to reject any network program in option time in order to substitute another program "of outstanding local or national importance." It may also reject or refuse any network programs offered which the station "reasonably believes to be unsatisfactory or unsuitable" or, even though the program has already been contracted for by the station, which the station believes "is contrary to the public interest." Those provisions have been construed by CBS Television to permit wide discretion to the station to reject network programs which the station believes will not serve the local audience as well as a nonnetwork program which the station proposes to broadcast. ${ }^{50}$

The precise limits of the respective rights of the CBS Television Network and its affiliates under these provisions of the option-time clauses have never been fully delineated, because in practice there has been no necessity for it. Rather, acceptance by stations of network programs has been based on the cooperation which is inherent in the basic partnership relation which exists between the network and its

contrary to the public interest, or (B) from substituting a program of outstanding local or national importance. CBS Television may, also, substitute for one or more of the programs offered hercunder other programs, sponsored or sustaining, of outstanding local or national importance, without any obligation to make any payment on account thereof (other than for the substitute program, if the substitute program is sponsored). In the event of any such rejection, refusal or substitution by either party, it will notify the other by private wire or telegram thereof as soon as practicable."

${ }^{4}$ FCC Rules and Regulations, 47 C.F.R. $\$$ 3.658(d) (Supp. 1956).

10 FCC Report on Chain Brondcasting (May 2, r941).

${ }^{50} \mathrm{CBS}$ Television has construed the option-time provisions to be inapplicable to any program which occupies a period straddling option time and nonoption time. Thus, for example, the periods betwecn Io and II P.M. (E.S.T.) on Mondays and Wednesdays, which are now occupied by hour-long programs, and the period between 9:30 and II P.M. (E.S.T.) on Thursdays, which is occupicd by an hour-and-ahalf program, are not subject to network option time. Contrary to contentions that have been advanced, option time, under the construction followed by CBS Television, is contracted rather than expanded when a single program in part covers option time and in part covers nonoption time. 
affiliates. There has been no rigid invocation of its option rights by the network, and affiliates' schedules are studded with nonnetwork programs in option time. In practice, it is utilized and adjusted for the benefit of both the network and the affiliates.

Either option time or some equivalent tool is essential to the proper functioning of the network. Without some reasonable assurance of general clearance by stations, the effectiveness of the over-all, day-in, day-out, week-in, and week-out network schedule would be eroded.

It would take the defection of only a few key stations in major markets to deprive a network television advertiser of so substantial a part of his circulation that the program would not continue and thus would be lost not only to the network, but, far more important, to the other vast majority of stations which need and want the program. In addition to the network, both the public and the stations in the smaller markets would suffer most acutely, if any major pattern of nonclearance developed.

It cannot be stated with certainty that any such fatal erosion would occur overnight; indeed, that is improbable. But equally, there can be no certainty that over a period of time, such erosion would not occur. If it did, the blow to networking, with all that networking means in the way of major programs and programs which must be carried live, would be fatal. It is wholly possible that an entire schedule could be eroded by a pattern of nonclearance that would checkerboard across the schedule. It is hardly likely that key stations would pick the same programs and the same time periods for nonclearance. What would be more likely to occur is that some key stations would refuse to clear during one half-hour, another group of key stations might pick another half-hour, and another still a different half-hour. If the stations were in enough large markets, each network time period would then become unsalable to national advertisers. Obviously, no network could afford to program, with a quality schedule, so many time periods on a sustaining basis; as has been shown previously, the costs of high-quality programming on a sustaining basis for one nighttime hour, seven days a week, would be between $\$ \mathrm{I}_{3}$ million and $\$ 15$ million. The alternative would be to curtail network service and thus throw the burden of programming and large costs on the scores of smaller stations which had not refused to clear.

Moreover, once a time period became sustaining because of the loss of an advertiser, it would be difficult for the network to recapture the period, because in many instances key stations might well have sold it to national spot and/or local advertisers. 51 The station's contracts for those programs would have varying termination dates; hence, without option time, re-entry of the network would have to await the last termination of the last group of stations. But that date may be so late that other stations meanwhile will not have waited, and cannot be expected to wait, and in turn

${ }^{61}$ It is one of the phenomena of the broadcasting business, illustrated by the recent history of radio, that in periods of decline, network business is hit first and hardest. A national advertiser's diminished budget is normally first withdrawn from the network and dcvoted instead to a more limited number of stations in key markets. 
will have entered into new contracts. By then, the network advertiser is likely to be lost.

Essentially then, option time is not a rigid right, explicitly exercised in particular cases by the network. Rather it is a limited protection against erosion, which can be used if it ever becomes necessary. It is a safeguard against the destruction of networking.

It is of first importance in considering option time and its justification to recognize that it is the result of negotiations between stations and the network. It is not an abdication by stations of their programming responsibility; rather, it is a voluntary recognition by them that the network is a reliable source of a substantial portion of an over-all effective weekly schedule, with appropriate balance of the various elements which are necessary to successful broadcasting in the public interest. Since, by affiliating with a station, a network, in effect, agrees to use its best efforts to sell the station's time and make programs available to it, it naturally follows that the station will agree to make time available when the network does sell its time.

It has been claimed that networks should not be able to have option time since independent program producers do not have it. The fact that option time has not been granted by stations to independent program producers results from neither legal restrictions nor compulsion on the stations. Stations are free to deny option time to networks and to grant it to any other program source or sources. Stations will exercise that right at such time as other sources provide a more attractive over-all product.

It has been urged, too, that regardless of its importance to networking, the time option has such restrictive consequences on other segments of the industry as to require its elimination.

a. It is contended that as a result of option time, affiliated stations do not exercise the choice in program selection required of them as licensees. This is based partly on the assumption that the right to refuse to broadcast a network program or to substitute a local program of special community interest is a mere technicality and seldom exercised. This is not the case. It is a broad and practical right, effectively and not infrequently invoked. It is not limited to the rejection of network programs which the station believes are "contrary to the public interest"; it extends to network programs which the station finds are "unsatisfactory or unsuitable" for its purposes. The network program may also be rejected in favor of the program of another network. As noted above, the option right of the network is treated flexibly by it, and its application is always subject to negotiation with the station.

Another contention as part of the argument that option time is inconsistent with station responsibility is that network time options constitute "blind selling," since the station licensee rarely sees the program before it is broadcast and cannot judge whether the program is in the public interest.

\footnotetext{
${ }^{62}$ As has been pointed out, network programs are not sold to affiliated stations. The programs are sold to the advertisers for broadcast purposes.
} 
CBS Television Network affiliates receive advance descriptions of all network program series before the series begin, and, in some instances, closed circuit previews of new programs are furnished. After a network series begins, each ordered station receives a detailed description of the following week's program several days before it is to be broadcast. That description and a station's confidence in the judgment of the network are usually adequate for the station to make an informed decision as to the suitability of the individual program. When an affiliate is not satisfied with the regular description, either before or after a series begins, it can and does ask for a more detailed description of the forthcoming program or series, and the network, of course, does its best to satisfy those requests. And, at any time, whether before or after the network series begins, an affiliate can reject a network program which is "unsatisfactory or unsuitable" for the station's purposes.

The information which stations receive about nonnetwork distributed programs is not substantially different. Even when a station views a pilot of a syndicated film series, it does not preview every film in the series before it contracts to purchase and broadcast the entire series. And, unlike the case of network programs, the purchase of the syndicated series does not normally carry with it the right to return if it is found to be unsatisfactory or unsuitable to the station.

b. Another contention is that option time has restricted the growth of nonnetwork program sources. ${ }^{53}$

There are a very large number of independent program producers, both large and small. Some are subsidiaries or affiliates of major Hollywood motion-picture producers. Some are producers who have expanded into television from the radio syndication business. Some are talent agencies which in their productions utilize the talent they represent. Some are organizations which have come into being in recent years and devote themselves solely to production for television.

While there has been no over-all survey of its total components and product, it is clear from published sources that the film syndication business is large, with a great many program suppliers. The business and its product have grown rapidly over the last few years.

Thus, the Television Factbook for 1948 listed 192 independent programs, sources and services known to be acting as suppliers to television at that time. In the 1956 Factbook, 8ro sources were listed, of which apparently almost 500 were newcomers since 1953. According to the Television Magazine Data Book (1956), the number of syndicated films and film series produced especially for television and available for distribution increased from 85 in 1952 , to 259 in 1955 , and to approximately 400 in I95்..$^{54}$

${ }^{63}$ Programs produced by nonnetwork sources fall into two general categories: $(x)$ live or film programs for broadcast over the networks, and (2) syndicated film destined for national spot or local use on individual stations.

${ }^{84}$ A recent article in The Billboard, Aug. 12, 1957, p. 42, reported that there would be an increase of at least $25 \%$, and possibly as much as $40 \%$ in first-run products made available for syndication in the fall of 1957 . Thirty-one first-run film major series are listed as available for sale in 1957, as contrasted with 22 in each of the 3 preceding years. 
Nonnetwork program sources are extensively used as a part of the network's programming services both during and outside option hours. ${ }^{55}$ Network broadcasts are an important outlet for independently produced programs. Further, to the extent that network programming, to which option time is so essential, increases the prestige and revenues of a station, advertisers are attracted and stations may expand their total broadcast hours. Both result in the increased use of nonnetwork produced programs.

c. The charge has been made that option time has unduly restricted time availabilities for nonnetwork programs. This is based on the premise that all the desirable station time during which their programs might be given exposure has been pre-empted.

The growth in the number of independent producers and the increase in the number of television programs they are producing belie this contention. The fact is that (a) syndicated programs clear Class A time (the evening viewing hours) in substantial numbers; (b) other viewing hours (the so-called Class B and Class C time) are adequate for syndicated film as well as networks; and (c) network-affiliated stations with option time make greater use of first-run syndicated film than do unaffliated stations where no option time obtains.

$d$. Finally, it is charged that option time has restricted the ability of nonnetwork advertisers to use television. This is not borne out by the evidence. There has been a steady and substantial increase, over the past five years, in the volume of television expenditures by national spot and local advertisers: from \$151.5 million in 1951 to $\$ 580.2$ million in 1956.56

\section{Option time and the antitrust laws}

It has also been contended that the option-time practice of the networks violates the antitrust laws. The argument, in the main, is that this practice is similar to that condemned in United States v. Paramount Pictures. ${ }^{57}$ There, the Court found to be illegal "the practice of licensing or offering for license one feature or group of features on condition that the exhibitor will also license another feature or group of features released by the distributors during a given period." 58 This tie-in practice, referred to as "block-booking," was found to be illegal because "the result is to add to the monopoly of the copyright in violation of the principle of the patent cases involving tie-in clauses." ${ }^{\text {"5o }}$ The Paramount case has no applicability to the option time practice for at least three reasons:

a. Programs are not "block-booked" to the stations. The fact is that the network does not sell programs to stations. The stations merely furnish their facilities during option time for the showing of network programs and the network compensates the stations on the basis of the time used. The customers of the network-the purchasers-are the advertisers. Programs-or time-are sold to them on a unit basis.

${ }^{\circ}$ See infra pp. 607-09.

${ }^{56}$ Printers Ink Magazine, Aug. 23, 1957, p. 55, citing McCann-Erickson, Inc. estimate.

${ }^{67} 334$ U.S. 13 I (1947). ${ }_{68}^{50}$ Id. at at 158 . 156 . 
There has been no suggestion that block-booking exists between networks and advertisers.

b. No network has the necessary dominance or leverage in any item to make a tie-in sale of it invalid under the tying rule of Times-Picayune Publishing Co. v. United States, supra.

c. Finally, option time is a reasonable device under all the circumstances. As has been shown, it has not been restrictive in its effect, and there is strong business justification for it. In Paramount, the Court was unable to find any business justification for the block-booking practice.

D. The Network's Use of Network-Produced Programs and Their Control of Time

It has been charged that the networks discourage, or discriminate against, nonnetwork produced programs by making valuable time periods available only to network produced programs. CBS Television follows no such practice; there is no such discouragement or discrimination..$^{60}$

The facts refute the charge. An analysis of the hours of CBS Television Network sponsored programming during a sample week in each of the past five years during. the 6:00-II:00 PM time segment and during the full broadcast day, showing the percentages of (a) programs produced and wholly owned by CBS, (b) programs produced either by CBS, jointly by another person and CBS, or solely by another person, in which CBS had an interest together with one or more other persons, and (c) programs produced by persons other than CBS in which CBS did not have any financial or proprietary interest, gives the following results:

6:00-II:00 PM time segment:

(a)

I953

I954

1955

1956

x957
$26.6 \%$

25.2

26.1

20.7

I8.9 (b)

$44.2 \%$

39.2

37.7

36.0

37.9 (c)

$29.2 \%$

35.6

36.2

43.3

43.2

Full broadcast day:

(a)

I953

I954

I955

1956

I957

$21.5 \%$
22.0
17.2
13.1
II. 5

(b)

$38.6 \%$

35.6

37.5

38.5

40.2 (c) $39.9 \%$

42.4

$45 \cdot 3$

48.4

48.3

\footnotetext{
${ }^{60}$ There is one category of programs which CBS Television insists be produced under its own supervision and control: As a matter of policy, and in order to maintain direct responsibility in the public interest, the CBS Television and Radio Networks have always maintained the production, supervision, and control over all its news and public-affairs programs. This policy is based on the belicf that only in this way can the network fulfill its responsibilities of maintaining its standards of objectivity and over-
} 
Thus, in both the prime evening viewing hours and during the entire broadcast day, a very substantial percentage of sponsored programs on CBS Television Networks are those produced and owned by persons entirely independent of the network. ${ }^{61}$

Comparison of hours of programs produced by CBS Television and outside sources does not alone reveal the full story of the opportunity of outside producers to have their programs broadcast over the network. An analysis of the amounts paid by advertisers for commercial programs broadcast on the CBS Television Network during 1955 reveals that advertisers paid out almost twice as much for programs produced wholly by outside producers as they did for programs produced by CBS Television and programs produced by CBS Television in association with independent producers. It is estimated that during an average week, advertisers paid $\$ 1,170,000$ for programs produced wholly by outside sources, $\$ 520,000$ for programs produced by CBS Television alone, and $\$ 130,000$ for programs produced by CBS Television in association with independent producers. For the year 1955 , it is estimated that $\$ 61,000,000$ was paid for programs produced wholly by outside sources, $\$ 27,000,000$ for programs produced by CBS Television alone and $\$ 7,000,000$ for programs produced by outside producers in association with CBS Television.

Demonstrably, therefore, the CBS Television Network does not exclude independent program packages from its program schedule. Indeed, any such policy of exclusion and discrimination would be suicidal because it would weaken, if not destroy, the asset on which a network stands or falls-the quality of its programming. Precisely for that reason, the policy of the CBS Television Network has always been, and will continue to be, to schedule the right program in the right place regardless of its source.

But, in order to fulfill its responsibility to its affliates and to the public, a network must engage in a certain amount of program production. Only in this way can there be assurance of day-in, day-out, and week-in, week-out high-quality programs. The network cannot perform its functions in this area if it must stand and wait for programs from outsiders who do not have the same continuous relationship which

all balance among significant viewpoints on public issues. In addition, there are two types of programs which may be said to be tied, to a greater or lesser degree, by CBS Television to particular time periods: (I) multiple-sponsorship programs; and (2) "anchor" programs. Multiple-sponsor programs and the sales patterns involved are such that after one or more sponsors have agreed to purchase a participation or sponsor one of the several segments, the time obviously cannot be sold to another sponsor for a different program. In this sense, so long as the programs remain in their tume period, one of the sponsors or a potential sponsor cannot, as a practical matter, substitute a different program during the time period. "Anchor" programs are the anchors for the night's schedule; they become anchor programs through proven popularity. Normally, since the schedule is built around them, the CBS Television Network would be reluctant to sell the time periods which they occupy for programs of a different nature. If, however, their strength and popularity should decrease, or if some other programs of clear merit were proposed, the list of anchor programs would change. In fact, such changes have occurred. It may be noted that a program qualifies as an anchor program on its merits and irrespective of its source.

${ }^{61}$ It should be recalled that, initially, virtually all television program production was undertaken by the networks. Nonnetwork production has increased as the risks have decreased. 
the network has to the broadcasting industry, to stations, and to the viewing public. Those basic facts have long since been emphasized by the Federal Communications Commission itself which criticized networks for not engaging in program creation and production and hence failing to exercise their programming responsibilities. ${ }^{62}$

An analogous charge has been made that the networks utilize their control of time to obtain substantial concessions in the way of financial interests or subsidiary rights from independent producers. This charge is equally fallacious. The fact is that the CBS Television Network acquires a financial interest in an independentlyproduced (or more often, a not-yet-produced but conceived) program only when the outsider submits an idea or a plot and, to bring the program to completion, the CBS Television Network incurs financial obligations, either directly or indirectly, through contribution to the creative development and production of the program. In no case has the CBS Television Network ever imposed as a condition of acceptance of a program, or of making time available for it, a requirement that it be granted a financial interest or be permitted to invest in the program.

\section{IV}

\section{Conclusion}

In this article, we have considered in broad outline the economics of networking and some of the principal practices which are part of an operating television network. These practices, together with other practices not specifically commented on herein, such as network affliation practices and network ownership of stations, are closely interrelated. No part can be examined in isolation from the others. A network must be considered as an entity. The dangers of considering it only as a set of disrelated parts to be juggled around any which way are most considerable.

While the present practices of the networks are defended in this article as having been necessary to the realization of television's full potential, this does not mean that these practices will or must continue forever in precisely their present form. In an industry as dynamic as television, it is impossible to foretell accurately its future shape. Hence, this article is not to be interpreted as insisting on the immutability of present network practices. It does assert, however, that such practices are not

09 The FCC stated: "Experience has shown that in general advertisers prefer to sponsor programs of news and entertainment. There are exceptions; but they do not alter the fact that if decisions today were left solely or predominantly to advertisers, news and entertainment would occupy substantially all of the time. The concept of a well-rounded structure can obviously not be maintained if the decision is left wholly or preponderantly in the hands of advertisers in search of a market, each concerned with his particular half hour, rather than in the hands of stations and networks responsible under the statute for over-all program balance in the public interest.

"A device by which some networks and stations are seeking to prevent program imbalance is the 'package' program, selected, written, casted and produced by the network or station itself, and sold to the advertiscr as a ready-built package, with the time specified by the station or network. In order to get a particular period of time, the advertiser must take the package program which occupies that period. This practice, still far from general, appears to be a step in the direction of returning control of programs to those licensed to operate in the public interest. . ." FCC, Public Service Responsibility of BROADCAST LICENSEES 13 (1946). 
only proper, but were, indeed, an essential ingredient in the growth of a healthy television industry. In light of the overwhelming acceptance by the public, stations, and advertisers of television in its present form, the burden of proof that something better (instead of only something different) can be achieved through a change in networking practices inevitably rests on him who makes the proposal. 